Open Access

\title{
Building Flexibility Management
}

\author{
Arto Saari*,1 and Pekka Heikkilä ${ }^{2}$ \\ ${ }^{I}$ Faculty of Engineering and Architecture, Dept. of Structural Engineering and Building Technology, Helsinki University \\ of Technology, Finland; ${ }^{2}$ AIR-IX Talotekniikka Oy, Finland
}

\begin{abstract}
A building may have three types of flexibility: a) service flexibility is important to the building's users, b) modifiability interests especially the owner, and 3) long-term adaptability is a key factor especially in the stratification of the urban structure and the cultural environment. A new indicator, the Flexibility Degree, was developed as part of this study to measure building modifiability. Clear phasing of the design process facilitates consideration of modifiability in the construction process. In the goal-setting phase the design team analyzes the client's expressed needs and commits together with representatives of the client to set flexibility goals. In the design solution phase the designers work out a solution proposal, a modifiability concept, which describes the principles of how flexibility is implemented in different parts and systems of a building. Only in the third phase, the implementation design phase, are detailed technical plans drawn for implementing the solutions.
\end{abstract}

\section{INTRODUCTION}

"Flexibility must be paid special attention" or "spaces are to be flexible" are opinions voiced in connection with setting the goals of construction. The premise is understandable as such. Only change is permanent in today's world. But what do we gain by such goal setting? In construction proper attention has been paid primarily to solutions considered flexible such as movable partitions. The same solutions are also easily copied from one building to another though the needs of different organizations vary. It is generally believed that by selecting individual components or subsystems regarded as flexible, the desired flexibility can be achieved. But what is the desired flexibility? Is it an exact, measurable concept which can be assigned concrete design goals? How should goals be set? This paper outlines flexibility as a concept, gives it a definition and content, and describes a way of setting flexibility goals for buildings and assessing them. The article draws on the research conducted by the Laboratory of Construction Economics and Management at Helsinki University of Technology and AIR-IX Talotekniikka Oy and experience gained from numerous real-life projects. Preliminary research result has been presented in publication [1].

\section{MATERIALS AND METHODOLOGY}

Research method used in this study was mainly computational. The effects of the building flexibility were indicated with the aid of Net Present Value calculations. Also, a novel indicator Flexibility Degree was used in this study. The construction costs and the refurbishment costs were calculated with the cost level in the greater Helsinki area (January 2003). The costs were calculated using the Finnish Target Costs Procedure (type-of-space estimate). The calculation procedures are described in source [1].

*Address correspondence to this author at the Faculty of Engineering and Architecture, Dept. of Structural Engineering and Building Technology, Helsinki University of Technology, Finland; E-mail: arto.saari@tkk.fi

\section{RESULTS}

\section{Concept of the Building Flexibility}

Slaughter [2] has presented that the tree major type of change (function, capacity and flow) and the interactions among systems provide a framework in which to analyze the capacity of the facility to meet the performance requirements with respect to the value-added activities performed within or through the facility. A function is defined as the set of activities or components to achieve a specific objective. Functions can be performed by the facility itself or with respect to human activities. Capacity is defined as the ability of the facility to meet certain performance requirements, in either loads/conditions or volume. Flows are defined as the movements within and round a building relating to surroundings environment and its usage population.

The systems within a building can interact through various mechanisms, and the nature of these interactions and the systems themselves influence the flexibility of the building to respond to the different type of changes. The system interactions can be grouped into three categories: physical, functional and spatial [2].

Flexiblity is a property of a building that is realized to some extent in all projects, even if it had not been actually taken into account in goal setting. Until now the problem has been that flexibility has been perceived as an ambiguous, unmeasurable concept. Moreover, it means different things to different interest groups. The user is typically interested in the flexibility of the spaces used in daily activities whereas the owner has also reason to consider flexibility over the medium and long term. Unconsidered investment of resources in flexibility may lead to unnecessary expenditure that does not necessarily result in flexibility in connection with actual changes. On the other hand, rigid design solutions may increase dissatisfaction among users and unrentable space. Thus, flexibility is a key parameter in the real estate business. 
Flexibility can be affected most effectively by controlling design and construction. When the building is finished, the possibility to have an impact on its flexibility is much more constrained since it is implemented through frame solutions, floor heights, building services ductwork, etc. which are expensive to change afterwards.

Below follows an examination of the flexibility concepts from the viewpoints of the various parties to the real estate business. The user of spaces is interested in a different type of flexibility than the building owner (see Fig. (1)).

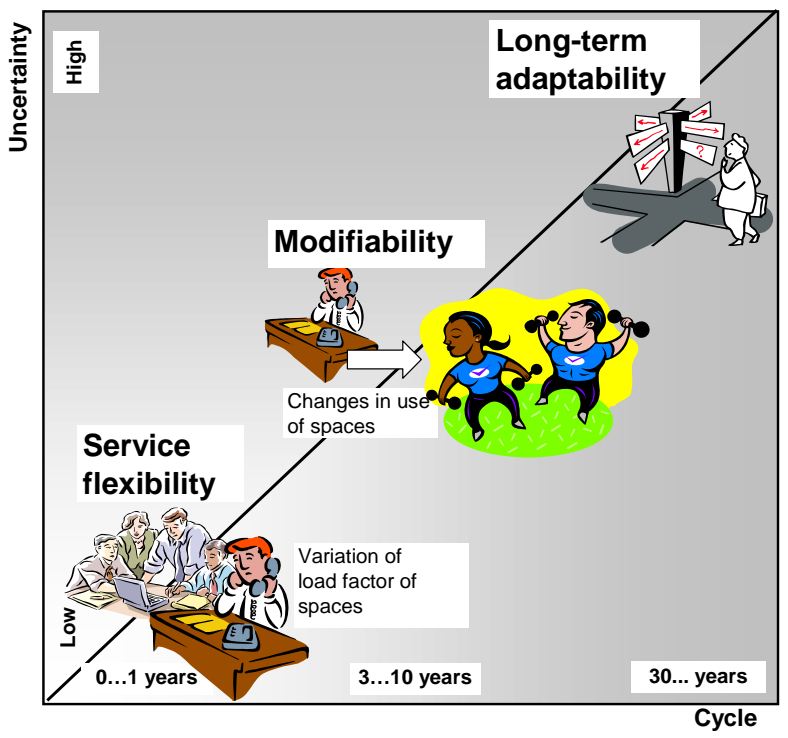

Fig. (1). Buildings have three types of flexibility: 1) service flexibility, 2) modifiability, and 3) long-term adaptability.

Service flexibility: This type of flexibility refers to the building's ability to adapt to recurrent quick changes in loading. Changes in loading are the result of, for instance, changes in the number of people in a space, changes in the activity conducted in a space, etc. Service flexibility affects strongly the productivity of the activity in the space. Thus, it is especially important for users. It can be improved by, for instance, movable partitions and adjustable ventilation.

Modifiability: Modifiability of a building refers to its capacity to meet the changing needs of its users. Needs change, for instance, as the users change or the business of current users changes. This type of flexibility is an especially important property for the property owner. It can be improved by, for instance, "loose" dimensioning of building services and system walls.

Long-Term Adaptability: Long-term adaptability of a building refers to its adaptability to unknown activities and uses. Adaptability is an important property for the property owner, for instance, when buying or selling a building. It is also a major factor especially from the viewpoint of urban structure and the environment. The long-term adaptability of old industrial properties has been particularly good thanks to high floor heights and long spans. Their conversion to office and residential use has been possible and relevant in several recent construction projects. The adaptability of a building can be assessed primarily by comparing certain of its proper- ties to "universal" criteria. Adaptability depends on, for instance, floor height, spans, permissible floor loads and, for instance, a building's location in the community structure.

\section{Flexibility Degree}

A new indicator, the Flexibility Degree (FlexD), was developed as part of this study to measure building modifiability. The Flexibility Degree can be made use of in design management and, especially, in profitability comparison of implementation alternatives. Flexibility Degree can be determined for an individual space, a space unit, or an entire building. Flexibility Degree is determined by subtracting Rehabilitation Degree (RD) resulting from the renovation work from one hundred percent, i.e. $\operatorname{FlexD}(\%)=100 \%-$ $\mathrm{RD}(\%)$. Rehabilitation Degree refers to the costs of rehabilitation, as a percentage of new construction costs, required to produce quality corresponding to the spatial standards of new construction.

Example of Flexibility Degree assessment: When viewing the design solution of a certain building, it was concluded that if the office space was to be converted into a dressing room, the internal surfaces and built-in fittings would have to be renewed. The renovation costs of spatial alteration were assessed at $€ 350 / \mathrm{m}^{2}$ while new construction costs were set at $€ 1,250 / \mathrm{m}^{2}$. Thus, Flexibility Degree is: 1 $350 / 1250=72 \%$.

If the office space of the same building were to be converted into a washing facility, the space would have to be completely overhauled. Renovation costs were estimated at $€ 1,500 / \mathrm{m}^{2}$ and new construction costs at $€ 2,100 / \mathrm{m}^{2}$ resulting in Flexibility Degree of: $1-1500 / 2100=29 \%$. The office space of the example converts considerably more flexibly into a dressing room than a into washing facility.

\section{Flexibility Management in the Design and Construction Process}

Clear phasing of the design process facilitates consideration of flexibility in the construction process. As earlier stated, today's methods are solution-oriented. This is due the fact that clear project-specific goals have not been set. Thus, designers and implementers offer universal technical solutions which they regard as flexible. The solutions offered by designers may vary as to flexibility by fields of design. The architect's space arrangement may allow a quite large flexibility, but, for instance, the principle of air distribution might not allow changes in the room plan without major changes in building services technology.

A construction process that takes modifiability into account consists of three distinct phases (Fig. (2)). The same division in three is generally used in construction design processes. In the goal process the design team analyzes the client's expressed needs and commits together with representatives of the client to set flexibility goals. In the design process the designers work out a design-conception proposal, a modifiability concept, which describes the principles of how flexibility is implemented in different parts and systems of a building. Only in the third phase, the implementation design phase, are detailed technical plans drawn for implementing the solutions. 


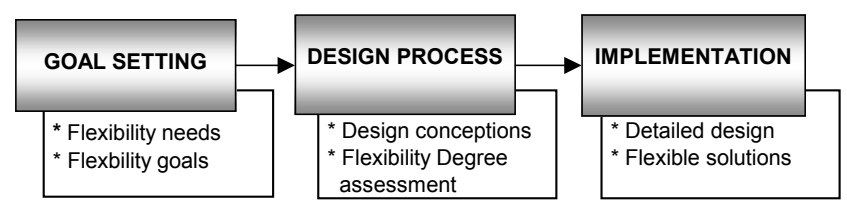

Fig. (2). A construction process that takes building flexibility into account consists of three distinct phases.

As the process proceeds, the client-focus changes between user and owner, which should be considered, for instance, in the visualization and documentation principles. The goal process is space-oriented. The system process is more procurement- and implementation-oriented where the owner is the focus of attention. The aim of implementation design, on the other hand, is to produce the plans and data that serve construction and maintenance from solutions designed earlier in the process. The design process and its phasing has been dealt with in more depth in the ongoing Design process development project (SuPro) of the Finnish Association of Consulting Firms (SKOL).

\section{Examples of Building Flexibility Management}

The first example involves the setting of modifiability goals at the project planning phase of construction project and the second one has to do with the comparison of design conceptions of different grades of flexibility at the construction design phase.

\section{Example of building flexibility goal setting}

At the project planning phase of both new construction and renovation projects flexibility goals should be set for buildings. The goals cover the scope of rental units, their spatial properties, and the response times to changes in them.

Our example project is a multi-user office building. The rental space goal set at the project planning phase is 3,940 $\mathrm{m}^{2}$. The tenants are two companies - one wants open office space and the other one cell office space (Table $\mathbf{1}$ ).

We must also allow for the fact that the size of the rental unit may vary from 200 to $3,340 \mathrm{~m}^{2}$ and that the office units are convertible a) into open or cell offices (response time 2 days), b) a fitness gym (response time 14 days), c) a restaurant (response time 90 days).

\section{Example of building design phase}

Goals set at the project planning phase can be attained through different design conceptions. Here, we compare three design conceptions different as to their Flexibility Degree. Differences between the costs of alternatives discounted to the present facilitate drawing of conclusions.

The principles of design conceptions are:

- In Alternative A is to dimension ventilation ducts and equipment strictly in accordance with the current use of spaces

- In Alternative B they are dimensioned to suit an open office, and

- In Alternative $\mathrm{C}$ according to the requirements of a fitness gym
Table 1. Project Example: Current Need of Spaces

\begin{tabular}{|c|c|}
\hline Spaces: & $\mathbf{m}^{2}$ \\
\hline \multicolumn{2}{|l|}{ Office I: } \\
\hline Open office & 1,440 \\
\hline Meeting rooms & 112 \\
\hline Toilets & 38 \\
\hline Storages & 80 \\
\hline Corridoors & 100 \\
\hline Rental space I total & 1,770 \\
\hline \multicolumn{2}{|l|}{$\underline{\text { Office II: }}$} \\
\hline Office rooms & 1,440 \\
\hline Meeting rooms & 112 \\
\hline Toilets & 28 \\
\hline Storages & 80 \\
\hline Corridoors & 500 \\
\hline Rental space II total & 2,170 \\
\hline \multicolumn{2}{|l|}{ Other spaces: } \\
\hline Stair cases & 220 \\
\hline Bomb shelter/storages & 75 \\
\hline Technical & 300 \\
\hline Other space total & 595 \\
\hline$\underline{\text { TOTAL }}$ & 4,535 \\
\hline
\end{tabular}

- In all alternatives, partitions are implemented by movable system walls.

The construction costs of Alternative B are $€ 40,000(0.5$ $\%$ ) higher than those of Alternative A while the costs of Alternative $\mathrm{C}$ are $€ 130,000$ (1.5\%) higher than those of $\mathrm{A}$. Interest (real) on capital is set at $6 \%$.

Flexibility Degree of Alternative A for conversion from cell office space into open office space is $74 \%$. Flexibility Degrees of Alternatives B and C are $100 \%$. If all cell office space is converted into open offices ( $47 \%$ of rental space), the renovation costs are $€ 780,000$ with Alternative A; Alternatives $B$ and $C$ involve hardly any renovation costs. If said conversion from cell to open office space occurs 0-50 years into the future, Alternative $\mathrm{B}$ is financially more profitable than Alternative A. Alternative $\mathrm{C}$ is the worst one (Fig. (3)).

Flexibility Degree of Alternatives A and B to conversion from open or cell office space into a fitness gym is $53 \%$ while that of Alternative $\mathrm{C}$ is $92 \%$. If half of the open or cell office space is converted into a fitness gym $(20 \%$ of rental space), the resulting renovation costs are $€ 510,000$ in the case of Alternatives A and B, and $€ 80,000$ in the case of C. If such a conversion from open or cell office space into fitness gym occurs $0-20$ years into the future, Alternative $\mathrm{C}$ is financially more profitable than Alternative A. Alternative B is the worst one. 


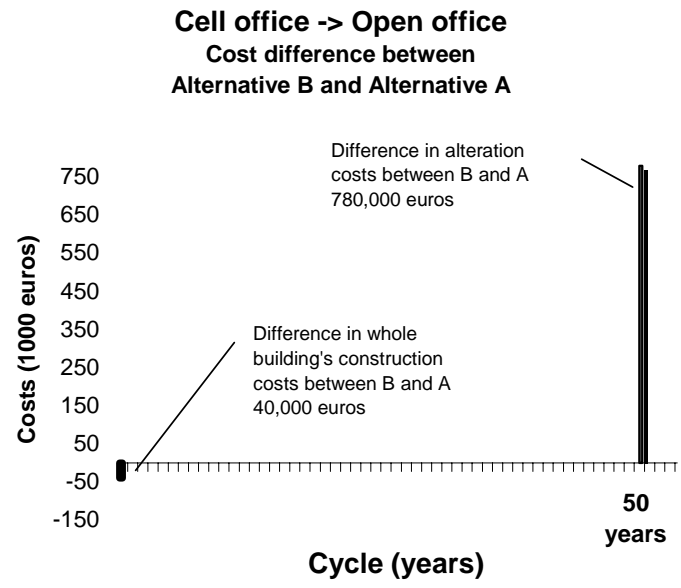

Cell office -> Fitness gym

Cost difference between

Alternative $\mathrm{C}$ and Alternative $\mathrm{A}$

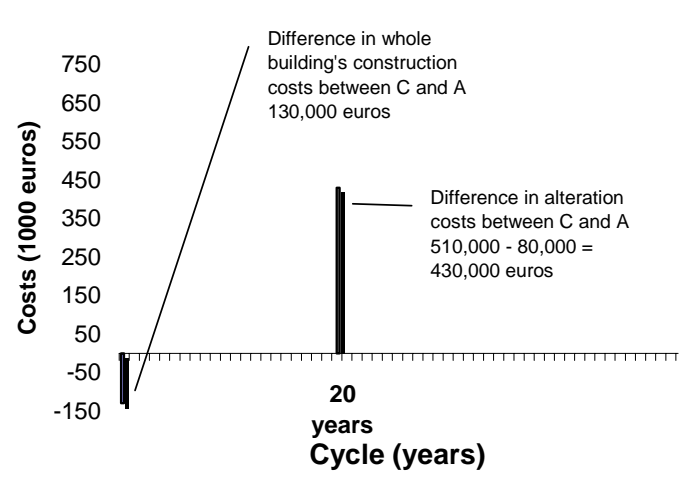

Fig. (3). Project example: If a conversion from cell office to open office space occurs 0-50 years into the future, Alternative $\mathbf{B}$ is financially more profitable than Alternative A (above). If a conversion from open or cell office space into fitness gym occurs 0-20 years into the future, Alternative $\mathbf{C}$ is financially more profitable than Alternative A (below).

Flexibility Degree of Alternatives A, B and C to conversion from open or cell offices to a restaurant dining room and its kitchen is $32 \%$. If $12.5 \%$ of the open or cell offices are converted into a restaurant dining room and kitchen $(5 \%$ of rental space), the resulting renovation costs with Alternatives $A, B$, and $C$ are $€ 370,000$. In this case Alternative $A$ is the most profitable one and $\mathrm{C}$ the worst one.

The example calculations confirm the earlier statement that "universal flexibility does not exist". Although quite high degrees of flexibility were measured in certain situations (e.g. cell vs. open office), it does not necessarily mean that said space is universally flexible (cf. cell office vs. restaurant).

\section{Concept of Flexible Room Program}

Saari $[3,4]$, has been developed a concept "flexible room program". A flexible room program includes spaces allowed for in the construction phase, or where modification during use is allowed for. A floor-area range is presented for each type of space (see an example Table 2).

Table 2. Flexible Room Program [3]

\begin{tabular}{|c|c|c|c|}
\hline & $\begin{array}{c}\text { Range } \\
\mathbf{~ m}^{\mathbf{2}}\end{array}$ & $\begin{array}{c}\text { Size } \\
\mathbf{~ m}^{\mathbf{2}}\end{array}$ & Persons \\
\hline \hline Cell office & $300-1,600$ & $10-20$ & $20-150$ \\
\hline Open-plan office & $0-1,000$ & & $0-125$ \\
\hline Meeting rooms & $100-200$ & $20-50$ & \\
\hline Storage space & $200-400$ & $10-20$ & \\
\hline WC & $30-50$ & $2-10$ & \\
\hline etc. & $\ldots$ & & \\
\hline Total (fixed) & 4,000 & & \\
\hline
\end{tabular}

\section{CONCLUSIONS}

Flexibility is not a universal property of a building. Thus, no universal goals can be set for flexibility nor can "absolutely flexible" spaces be built. Flexibility is a relative property. We must determine which alternative use situations we should prepare for since it is not possible, in practice, to be prepared for arbitrary changes. Likewise, we must estimate acceptable conversion costs and disturbances to activities. Assessment of alternative use situations is, however, possible only in the quite short term, let's say under five years. On the other hand, we can prepare ourselves for the "unknown future" mainly by certain solutions related to the building frame.

A building may have three types of flexibility: 1) service flexibility, 2) modifiability, and 3) long-term adaptability. Service flexibility is important to the building's users. Modifiability interests especially the owner. Long-term adaptability is a key factor especially in the stratification of the urban structure and the cultural environment.

Building flexibility is a key parameter in the real estate business. It can and should be impacted already at the design phase of the building.

\section{REFERENCES}

[1] Y. Haahtela and J. Kiiras, Talonrakennuksen kustannustieto, Haahtela-kehitys Oy: Helsinki, 2003.

[2] E. S. Slaughter, "Design strategies to increase building flexibility", Building Research \& Information, vol. 29, pp. 208-217, 2001.

[3] A. Saari, "Systematic procedure for setting building flexibility targets", in Proceedings of the CIB Working Comission 070 Facilities Management and Maintenance Global Symposium 2002, J. Hinks, D. Then and S. Buchanan, Eds. CIB Proceedings: Publication 277, September 2002, pp. 115-122.

[4] A. Saari, M. Kruus, A. Hämäläinen and J. Kiiras, "Flexibuild - a systematic flexibility management procedure for building projects", Facilities, vol. 25, pp. 104-114, 2007.

(C) Saari and Heikkilä.; Licensee Bentham Open.

This is an open access article licensed under the terms of the Creative Commons Attribution Non-Commercial License (http://creativecommons.org/licenses/by-nc/3.0/) which permits unrestricted, non-commercial use, distribution and reproduction in any medium, provided the work is properly cited. 